\title{
Infection and Expulsion Rate of Intrauterine Contraceptive Device after immediate Post Caesarean Versus Interval Insertion
}

\author{
ZILLE HYDER SYED, MARYAM MATLOOB, RUBINA QASIM, WAFA NAJEEB \\ Department of obstetrics and gynecology, University Of Lahore, Mansoorah Teaching Hospital. Lahore
}

Correspondence to Dr. Zill e Haider, consultant gynecologist, email:zillesyed@hotmail.com.03047974760

\begin{abstract}
Aim: To compare the frequency of infection and expulsion following insertion of IUCD immediate post casarean to that of interval insertion in parturient undergoing elective caesarean section

Method: This Randomized controlled trial was conducted from 21 February to $20^{\text {th }}$ August 2010.

Results: It was observed that in immediate post cesarean group(Group A) expulsion rate was $8.1 \%$ and infection rate $7.2 \%$ where as in interval insertion group(Group B) expulsion rate was $10.9 \%$ and infection rate was $9.0 \%$. The difference of expulsion rate was statistically significant in two groups ( $p$ value 0.491 ) i.e expulsion rate was proven to be significantly higher in interval insertion group than immediate trans cesarean insertion group. The difference of infection rate was not statistically significant between two groups ( $p$ value 0.623) although infection rate was found to be higher in interval insertion group but not clinically significant difference was found.

Conclusion: Null hypothesis was rejected for expulsion rate of IUCD and a statistically significant increased expulsion rate was found in interval insertion group as compared to immediate post cesarean insertion group. Null hypothesis was accepted for infection rate after IUCD placement in two groups as no statistically significant increased infection rate was found between immediate post cesarean and interval insertion groups Keywords: Expulsion rate, infection rate,immediate post cesarean insertion,interval insertion.
\end{abstract}

\section{INTRODUCTION}

Pakistan is one of the most populous countries of the world where contraception is still a debatable and controversial issue $^{1}$. Contraception is being practiced by only 30percent of the population ${ }^{2}$.The reason behind this nonuse is unawareness, lack of access to family planning services and geographical and cultural limitations. Intrauterine contraceptive device (IUCD) is the second most common method of contraception in Pakistan, like many other countries worldwide, being used widely since 1965 . It is the most popular method of reversible contraception due to its low cost and high efficacy especially in developing countries. It is particularly useful for the women who wish to use a method that does not require regular motivation, husband's day to day participation and those women who are not suitable for hormonal method use ${ }^{3}$. Failure rate of IUCD is slightly more as compared to oral contraceptives. Around 85 million women are IUCD users worldwide. In Pakistan, its acceptability should be high due to its safety, convenience and cost effectiveness, but the problem related its unpopularity is lack of awareness with many queries and concerns associated.

Insertion of IUCD during caesarean section, right after childbirth is very attractive and acceptable for many reasons. As woman is not pregnant and this is the time she might be most willing and motivated for contraception as she has recently gone through all the tough long journey of gravity and child birth $^{5}$. She might be planning for contraception with high motivation and immediately after childbirth, hospitals are the most convenient and suitable place for her to get a reliable method of contraception With availability of skilled personnel and appropriate facilities. In developing countries post placental IUCD insertion is especially more applicable, as childbirth may be the only time for a healthy woman to visit the

Received on 13-01-2021

Accepted on 24-04-2021 hospital and chances of follow up for contraception may be remote.

However there are fears associated with trans cesarean insertion of IUCD, like perforation, expulsion and introduction of infection. As the number of cesarean is rising worldwide the choice of trans cesarean IUCD insertion is increasing for obvious reasons. Trans cesarean insertion is under direct vision so risk of perforation during insertion is very much reduced. As studies show although the risk of expulsion is greater when IUCD is inserted in postpartum period, but this can be significantly reduced by using proper insertion technique and early insertion i.e. post placental(within 10 minutes of delivery of placenta $)^{6}$. There is no increase in infection rates after immediate post placental IUCD insertion shown by international studies. One of very catchy benefit of post placental trans cesarean insertion is convenience of the women for not to wait till puerperium to start contraception which may result in marked reduction in unwanted or unplanned pregnancies ${ }^{7}$.

Although trans cesarean insertion of IUCD is getting popular in Pakistan but experience is still limited which needs to be studied a lot regarding its safety and routine use. Post placental IUCD insertion is very common method of contraception in Mexico, China and Egypt ${ }^{8}$. Studies done international and national platforms show increase in infection and expulsion rates in immediate post placental groups as compared to interval insertion but safety, compliance, patient satisfaction and effectiveness of immediate post placental insertion of IUCD is above any doubt. Studies on displaced IUCDs, uterine perforation and infection, all of which are more relevant to developing countries with poor post insertion follow up, are still lacking ${ }^{9}$. As randomized trials show Increasing cesarean section rates and awareness of contraception in women undergoing abdominal births, insertion of IUCD at the time of cesarean section is a very useful area of research ${ }^{10}$.

The objective of this study is to compare the expulsion and infection rates of trans cesarean IUCD insertion with 
routine six wks. post cesarean insertion so that the better method of contraception is safely practiced.

\section{MATERIALS AND METHOD}

It was a Randomized control trial, conducted in the obstetrics operating rooms and out-patient department of the Holy Family Hospital Rawalpindi from $21^{\text {st }}$ February, 2013 to $20^{\text {th }}$ August 2013. Sample size was calculated by WHO calculator software version 2.0 for estimating the difference between two population proportions with specified absolute precision. Power of test was $80 \%$, absolute precision required0.05. Anticipated population proportion (Interval Insertion) ${ }^{4}$. $2 \%$. Anticipated population proportion (Immediate Insertion) 10\%. Sample size 110 (in each group) was calculated by Non probability consecutive sampling technique

Inclusion criteria: All adult healthy parturient scheduled for an elective caesarean section and have consented for the IUCD insertion.

Exclusion criteria: Patients with the following diseases and conditions were excluded from the study as these are the high risk diseases which can either be potentially harmful for the patients or can jeopardize the accuracy of the results (to effect modifiers)

1. Emergency caesarean section: a high risk condition with increased risk of complications as compared to Elective Cesarean

2. Known cases of uterine tumor of any kind: as high risk condition where IUCD is contraindicated

3. Patients with acute, chronic or recurrent pelvic inflammatory disease: as IUCD is contraindicated. Secondly results would be jeopardized

4. Patients with congenital uterine anomalies: as increased risk of expulsion.

5. Patients with cardiomyopathies: cupper containing IUCD is not considered safe.

6. Patients giving history of dysfunctional uterine bleeding: a contraindication to IUCD

Data collection procedure: After taking ethical approval and informed consent, patients fulfilling inclusion criteria were randomly allocated by lottery method to either Immediate Insertion Group (Group A) where the IUCD was inserted within 10 mins of placental delivery during a caesarean section, or Interval Insertion Group (Group B) where IUCD was inserted six weeks after cesarean section. The insertion of IUCD was done by doctors of Holy Family hospital unit 2. Both the groups were followed for an interval of 6 weeks after insertion of IUCD.

Random allocation was done with sealed envelope technique. Patients were assigned to one of these groups by randomly selecting any envelop from the pool containing written alphabet A or B. Expulsion of IUCD was assessed by view of thread through the Cusco's vaginal speculum and later confirmed by pelvic ultrasound while the symptomatology of infection e.g.; criteria of SIRS, pelvic tenderness was observed on 6 weeks follow up. To avoid observational bias, the expulsion and symptoms of infection were examined by attending gynaecologist and recorded on the designed proforma by researcher. Moreover, the contact numbers of patients were recorded to ensure follow-ups.

Data analysis procedure: The data was analyzed using SPSS version 16.0. Frequency and percentages were calculated for categorical variables (expulsion and infection). Chi square was used to compare the frequency of expulsion and infection in both the groups and a P-value $<0.05$ was considered significant

\section{RESULTS}

In this study a total of 220 patients were included randomly and divided into two equal groups of 110 each via lottery method. In group A (immediate insertion group) Intrauterine contraceptive device was placed at the time of elective cesarean section, patients were followed after 6 weeks of cesarean section and they were assessed for expulsion of contraceptive device and signs and symptoms of pelvic infection. In group B patients (interval insertion group) were sent home after elective cesarean were recalled after 6 weeks for insertion of intrauterine contraceptive device and were followed up after 6 weeks for expulsion of IUCD and sign and symptoms of infection. Two groups were compared for these variables and results were withdrawn after analysis. The results for each variable which came after data analysis are presented below.

Expulsion Rate: In this study out of 220 patients, with 110 in each group, total expulsions of intrauterine contraceptive devices within 6 weeks follow-up time were 21(9.5\%).

Expulsion rate of IUCD in group A was $09(8.1 \%)$ and group $B$ was $12(10.9 \%)$ the difference between two groups was found to be statistically significant ( $p$ value 0.491 )

Infection Rates: In this study out of 220 patients, with 110 in each group, total incidence of infection found after intrauterine contraceptive devices placement was $18(8.1 \%)$ within 6 weeks follow-up time.

Infection rate after IUCD placement in group A was $08(7.2 \%)$ and group $B$ was $10(9 \%)$ the difference between two groups was not found to be statistically significant ( $p$ value 0.623 )

Age: In this study of 220 patients, the mean age of the patients included was 28.30 years with standard deviation of \pm 3.451 . Out of 220 patients in each group, the minimum age was 21 years the maximum age was 39 years. The age difference between two groups is not statistically significant ( $p$ value $0.726)$.

Figure 1: Infection rate in groups of patients

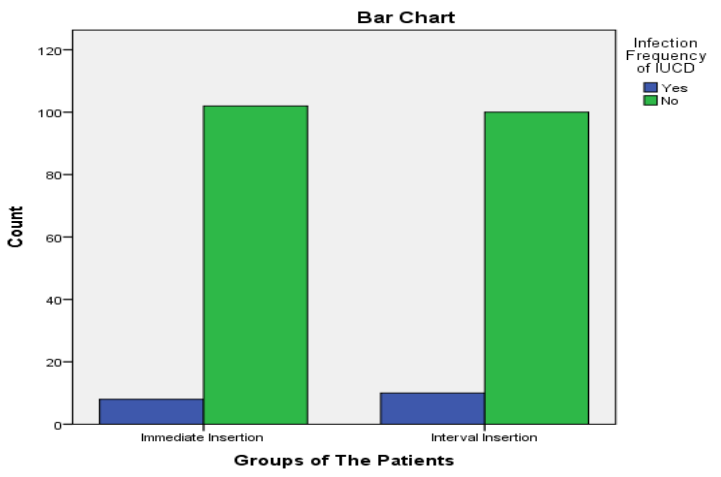

Table 1: Groups of The Patients

\begin{tabular}{|l|c|c|c|c|}
\hline & Frequency & Percent & Valid Percent & Cumulative Percent \\
\hline Immediate Insertion & 110 & 50.0 & 50.0 & 50.0 \\
\hline Interval Insertion & 110 & 50.0 & 50.0 & 100.0 \\
\hline Total & 220 & 100.0 & 100.0 & \\
\hline
\end{tabular}


Table 2: Expulsion Frequency of IUCD

\begin{tabular}{|l|c|c|c|c|}
\hline & Frequency & Percent & Valid Percent & Cumulative Percent \\
\hline Yes & 21 & 9.5 & 9.5 & 9.5 \\
\hline No & 199 & 90.5 & 90.5 & 100.0 \\
\hline Total & 220 & 100.0 & 100.0 & \\
\hline
\end{tabular}

Table 3: Groups of the Patients - Expulsion Frequency of IUCD

\begin{tabular}{|c|c|c|c|c|}
\hline & \multicolumn{2}{|c|}{ Expulsion Frequency of IUCD } & \multirow[t]{2}{*}{ Total } \\
\hline & & Yes & No & \\
\hline \multirow{2}{*}{ Groups of The Patients } & Interval Insertion & 12 & 98 & 110 \\
\hline & Immediate Insertion & 9 & 101 & 110 \\
\hline \multicolumn{2}{|l|}{ Total } & 21 & 199 & 220 \\
\hline \multicolumn{2}{|l|}{ Pearson Chi-Square } & $\mathrm{P}=.491$ & & \\
\hline
\end{tabular}

Table 4: Infection Frequency of IUCD

\begin{tabular}{|l|c|c|c|c|}
\hline & Frequency & Percent & Valid Percent & Cumulative Percent \\
\hline Yes & 18 & 8.2 & 8.2 & 8.2 \\
\hline No & 202 & 91.8 & 91.8 & 100.0 \\
\hline Total & 220 & 100.0 & 100.0 & \\
\hline
\end{tabular}

Table 5: Groups of the Patients - Infection Frequency of IUCD

\begin{tabular}{|c|c|c|c|c|}
\hline & \multicolumn{2}{|c|}{ Infection Frequency of IUCD } & \multirow{2}{*}{ Total } \\
\hline & & Yes & No & \\
\hline \multirow{2}{*}{ Groups of The Patients } & Interval Insertion & 10 & 100 & 110 \\
\hline & Immediate Insertion & 8 & 102 & 110 \\
\hline \multicolumn{2}{|l|}{ Total } & 18 & 202 & 220 \\
\hline \multicolumn{2}{|l|}{ Pearson Chi-Square } & & .623 & \\
\hline
\end{tabular}

Table 6: Descriptive Statistics of Age

\begin{tabular}{|l|c|c|c|c|c|}
\hline & $\mathbf{N}$ & Minimum & Maximum & Mean & Std. Deviation \\
\hline Age of the patient & 220 & 21 & 39 & 28.30 & 3.451 \\
\hline Valid N (listwise) & 220 & & & & \\
\hline
\end{tabular}

Table 7: Age distribution in both groups

\begin{tabular}{|c|c|c|c|c|c|}
\hline 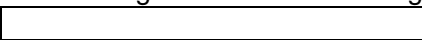 & Groups of The Patients & $\mathbf{N}$ & Mean & Std. Deviation & Std. Error Mean \\
\hline \multirow{2}{*}{ Age of the patient } & Immediate Insertion & 110 & 28.38 & 3.373 & .322 \\
\hline & Interval Insertion & 110 & 28.22 & 3.541 & .338 \\
\hline Using Independent Samples Test & $\mathrm{P}=.726$ & & & & \\
\hline
\end{tabular}

\section{DISCUSSION}

Pakistan has become one of the most populous countries of the world, where unmet need of contraception is increasing day by day. Intrauterine contraceptive device is one of the safest, reliable, long term, easily available, non coitus interrupting and easily reversible method of contraception. In Pakistan general awareness regarding contraceptive methods is still lacking and lots of efforts are needed in this sector of health care. Intrauterine contraceptive devices are considered the second most popular method of contraception in Pakistan. Intrauterine contraceptive device is one of the cheapest methods of contraception, contrary to the western world where intrauterine contraceptive devices are very expensive. In Pakistan IUCDs are available almost free in many areas of the country by efforts of family planning department of the government.

In this study it was noticed that there were general avoidance, misconceptions and fear regarding intrauterine contraceptive device use which made it unpopular among the women. Misconceptions regarding permanent subfertility, infections, uterine perforations, excessive weight gain , hormonal imbalance, sexual dissatisfaction, sexual dysfunction and systemic side effects were widely noticed in general public. Thus difficulties were faced during motivation and counseling of the patients to participate in the study.

In this study one of the parameter studied was the expulsion rate of intrauterine contraceptive devices which was compared between two groups, one with immediate post cesarean insertion group and other the interval insertion group. Expulsion rate was found to be lesser in the immediate post cesarean group to a clinically significant level with $p$ value less than 0.5 .. This result was not in correspondence with a study conducted in Karachi, in which expulsion rates were fund to be higher in the immediate post cesarean group. This difference of result may be due to improper technique used in the trans cesarean IUCD insertion leading to higher expulsion rates or may be coincidental.

The second parameter studied was infection rate comparison between the two groups. Infection rate was also found to be lower in the immediate post cesarean group. This result may be due to better compliance of the patient for antibiotic use immediately after LSCS leading to lower infection rates. In a study conducted in Karachi the infection rate was also found to be higher in the immediate post cesarean insertion group as compared to the interval insertion group, which may be due to unhygienic techniques of IUCD insertion or may be coincidental. 
In this study it was noticed that women were highly satisfied with this method of contraception on their follow up visits. There were no complaints of any pain, sexual dissatisfaction or dysfunction, difficulties in breast feeding, psychological issues or any systemic side effects. Only three women complained of heavy irregular bleeding, two of them responded well to the symptomatic treatment and only one women requested IUCD retrieval due to heavy bleeding.

IUCD expulsion was noticed more commonly in multiparous women, those undergoing LSCS for the first time and those who have previously given vaginal births. Expulsion rates were also higher in the patients in whom IUCDs were placed by junior obstetricians, probably due to improper technique of IUCD insertion. Infection rates were higher in women with poor hygienic conditions, those noncompliant to antibiotics and oral hematinic and those belonging to lower socioeconomic group. No co relation between ages of patients and infection or expulsion rates of IUCD were found in both groups under study.

Post placental IUCD insertion is highly recommended after this study as results show high motivation of women and their families for contraception at this time, assurance that patient is not pregnant, less side effects like infection or expulsion rates after immediate post-delivery insertion and least need for additional analgesia.

This study proved IUCD insertion to be one of the best methods of contraception with least side effects and high effectiveness. The best time to insert a contraceptive device is immediately after baby and placental delivery which makes it the safest, most appropriate and successful time of IUCD insertion.

\section{REFERENCES}

1. Hubacher D, Cheng D. Intrauterine devices and reproductive health: American women in feast and famine. Contraception 2004;69:437-46

2. Reeves MF, Smith KJ, Creinin MD. Contraception effectiveness of immediate compared to delayed insertion of intrauterine devices after abortion: a decision analysis. ObstetGynecol 2007;109:1286-94

3. Grimes DA, Lopez LM, Schulz HF, Van Vliet HAAM, Stanwood NL. Immediate post-partum insertion of intrauterine devices. Cochrane Database of Systemic Reviews 2010, Issue 5. Art. No.: CD003036. DOI: 10.1002/14651858.CD003036.

4. Bhutta SZ, Butt IJ, BanoK. Insertion of intrauterine contraceptive devices at caesarean section. J Coll Physician Surg Pak 2011;21(9):527-30

5. Heikinheimo O, Gissler M, Suhonen S. Age, parity, history of abortion and contraception choices affect the risk of repeat abortion. Contraception 2008;78:149-54

6. Stanek AM, Bednarek PH, Nichols MD, Jensen JT, Edelman AB. Barriers associated with failure to return for intrauterine device insertion following first trimester abortion. Contraception 2009;79:216-20
7. NS El Beltagy, EA Darwish, MS Kasem, NM Hefila. Comparison between Cupper T380 and Multiload 375 IUD in early postpartum insertion. Middle East FertilSoc J 2011;16:143-48

8. Heikinheimo O, Gissler M, SuhonenS. Age, parity, history of abortion and

9. contraceptive choices affect the risk of repeat abortion. Contraception 2008;78:149-54.

10. Goodman S, Hendlish SK, Reeves MF, Foster-Rosales A. Impact of immediate postabortal insertion of intrauterine contraception on repeat abortion. Contraception 2008;78:143-8.

11. Marrs RP, Kletzky OA, Howard WF, Mishell DR Jr. Disappearance of human chorionic gonadotropin and resumption of ovulation following abortion. Am $\mathrm{J}$ ObstetGynecol 1979;135:731-6.

12. Pakarinen $\mathrm{P}$, Toivonen J, LuukkainenT. Randomized comparison of levonorgestrel- and copper-releasing intrauterine systems immediately after abortion, with 5 years follow-up. Contraception 2003;68: 31-4.

13. Jones RK, Zolna MRS, Henshaw SK, Finer LB. Abortion in the United States: incidence and access to services, 2005. Perspect Sex Reprod Health 2008;40:6-16.

14. Thomas GS, Robert LS, Chales BB, et al. Contraception and sterilization. Clinical manual of gynaecology: 2nd ed. New York: McGraw-Hill Inc., 1992.pp.268-72.

15. Jamelle N. Retrieval of displaced IUDs in JPMC Pakistan. J. Obstet. Gynaecol., 1991;4:60-3.

16. Anita M, Frederick A, Gerald SB. Analysis of 100 cases of missing IUD strings. Contraception. 1978; 18:485-93.

17. Yeni E, Unal D, Verit A. Migration of intrauterine device as a cause of bladder stone. Brazil J Urol 2002; 28: 43-4.

18. Welkovic S, Costa L, Faundes A, Ximenes R, Costa C. Postpartum bleeding \& infection after postplacental IUD insertion. Contraception2001; 63: 155-8.

19. Ricalde RL, Tobias GM, Perez CR, Ramirez NV. Random comparative study between intrauterine device multiload Cu375 and $\mathrm{TCu} 380 \mathrm{~A}$ inserted in the postpartum period.GinecolObstetMex2006;74:306-11.

20. Thiery M, Van der Pas H, Delbeke L, Van Kets H. Comparative performance of 2 copper-wired IUDs (MI-Cu-250 and T-Cu-200)immediate postpartum and interval insertion. ContraceptDelivSyst 1980;1:27-35.

21. Mülller ALL, Ramos JGL, Martins-Costa SH, et al. Transvaginal ultrasonographic assessment of the expulsion rate of intrauterine devices inserted in the immediate postpartum period: a pilot study.Contraception 2005;72:192-5.

22. Zhou SW, Chi IC. Immediate postpartum IUD insertions in a Chinese hospital-a two year follow-up. Int J GynaecolObstet 1991;35:157-64.

23. Welkovic S, Costa LO, Faundes A, de Alencar X, Costa CF. Postpartum bleeding and infection after post-placental IUD insertion. Contraception 2001;63:155-8.

24. Celen S, Moroy P, Sucak A, Aktulay A, Danisman N. Clinical outcomes of early postplacental insertion of intrauterine contraceptive devices. Contraception 2004;69:279-82.

25. Gynecol 1982;143:29-35.

26. Grimes D, Schulz K, Van Vliet H, Stanwood N. Immediate postpartum insertion of intrauterine devices. [update of Cochrane DatabaseSyst Rev. 2001;(2):CD003036; PMID: 11406064]. [Review] [30 refs]Cochrane Database of Syst Rev 2003(1):CD003036.

27. Harris RP. Current methods of the US Preventive Services Task Force:a review of the process. Am J Prev Med 2001;20:21-5. 